"This is the peer reviewed version of the following article: [Functional Ecology ] which has been published in final form at [https://besjournals.onlinelibrary.wiley.com/doi/10.1111/1365-2435.13868] purposes in accordance with Wiley Terms and Conditions for Self-Archiving." 


\section{Functional Ecology}

\section{Water availability influences thermal safety margins for leaves}

Alicia M. Cook ${ }^{1}$, Neil Berry ${ }^{1}$, Kirsty V. Milner ${ }^{1}$, Andrea Leigh ${ }^{1}$

1 University of Technology Sydney, School of Life Sciences, PO Box 123, Broadway, NSW 2007, Australia

\section{Author Contributions}

AMC, KVM and AL conceived the ideas, all authors contributed to the design of methodology, NB collected the data, AMC analysed the data, AMC led the writing of the manuscript. All authors contributed critically to the drafts and gave final approval for publication.

\section{Author orcid numbers}

Alicia M. Cook, 0000-0003-3594-3220

Kirsty V. Milner, 0000-0001-8458-6253

Andrea Leigh, 0000-0003-3568-2606

\section{Acknowledgments}

This research was supported by Port Augusta City Council, South Australia; Friends of the Australian Arid Lands Botanic Garden (AALBG), an Ecological Society of Australia Student Research award to AMC, and an Australian Government Research Training Program Scholarship to AMC and KVM. The authors gratefully acknowledge Ronda and Peter Hall, Cory Keenan, Ryan Hayward, the Friends and staff at the AALBG, Port Augusta, South Australia, for assisting with recording measurements, tending plants, assisting in building rainout shelters, checking irrigation and allowing us to turn their tearoom into a field laboratory. Authors declare no conflicts of interest.

Data availability statement: Data available from the Dryad Digital Repository: https://doi.org/10.5061/dryad.tht76hf04 (Cook et al. 2021).

This article has been accepted for publication and undergone full peer review but has not been through the copyediting, typesetting, pagination and proofreading process, which may lead to differences between this version and the Version of Record. Please cite this article as doi: $\underline{10.1111 / 1365-2435.13868}$

This article is protected by copyright. All rights reserved 
MS ALICIA M COOK (Orcid ID : 0000-0003-3594-3220)

DR ANDY LEIGH (Orcid ID : 0000-0003-3568-2606)

Article type : Research Article

Editor : Sergio Rasmann

Section : : Applied Ecology. Ecophysiology. Functional

Corresponding author mail id: alicia.cook@student.uts.edu.au

\section{Abstract}

1. One application of plant physiological heat tolerance measurements is the assessment of vulnerability to increasing environmental temperatures under climatic change. $A$ thermal safety margin, the difference between physiological tolerance and environmental temperature, is a common metric for the assessment of plant thermal vulnerability. However, there are biological and methodological aspects to consider when evaluating thermal vulnerability that have the potential to substantially alter assessments. Two such aspects include the leaf to air temperature relationship and the scale at which air temperature data are collected.

2. We grew plants of a desert species, Myoporum montanum, in situ under waterstressed and well-watered conditions, measured their leaf temperatures and photosynthetic heat tolerance ( $T_{50}$ threshold) every third day over 12 days in summer. Thermal safety margins were calculated based on leaf temperatures and compared to those calculated with local and regional air temperatures. 
3. We found that heat tolerance and the thermal vulnerability assessment of a plant changed with water status. When water was readily available, plants maintained wide leaf temperature safety margins and displayed partial-homeothermy. When cooling via transpiration was limited, increasing leaf temperature corresponded with occurrences of leaf poikilo- and megathermy, higher heat tolerance, and narrower safety margins.

4. Our study shows high physiological heat thresholds are not necessarily reflective of wide safety margins, but instead can indicate a greater vulnerability and increased risk of heat stress exposure. Calculating thermal safety margins using air temperatures can also substantially alter margin widths. Where possible, the use of leaf temperatures in assessments of thermal vulnerability will lead to more meaningful vulnerability assessments. We recommend considering the source and temporal pairing of temperature measurements as well as plant water status, when measuring and interpreting plant thermal safety margins.

Keywords: thermal safety margin, heat tolerance, photosynthetic thermal tolerance, thermal tolerance, thermotolerance, thermal vulnerability, climate model predictions 


\section{Introduction}

To determine an organisms vulnerability to heat stress, a thermal safety margin, the difference between its physiological heat threshold and a temperature it experiences is often estimated (Deutsch et al. 2008; Sunday et al. 2014; O'Sullivan et al. 2017). Thermal safety margins are used to predict which species may be at a greater risk from heat stress now and under climate projections (e.g., Huey et al. 2009; O'Sullivan et al. 2017; Sastry \& Barua 2017; Gallagher, Allen \& Wright 2019).

For plants, physiological heat damage to photosystems is frequently measured with chlorophyll $a$ fluorescence techniques (Schreiber \& Berry 1977). A common heat damage threshold is $T_{50}$, the $50 \%$ decline in maximum quantum yield of Photosystem $\|\left(F_{V} / F_{M}\right)$, which is associated with irreparable damage to the photosystem apparatus (Schreiber \& Berry 1977; Downton \& Berry 1982). It therefore is logical to know and use leaf tissue temperatures to understand which plants are most likely to experience photosystem damage. However, air temperatures, which are more readily obtained, are typically used instead of leaf temperatures to determine plant safety margins (Curtis et al. 2016; O'Sullivan et al. 2017; Sastry \& Barua 2017). The use of air temperatures assumes that leaf temperatures, and hence the temperatures that leaf photosystems experience, are equal or very close to air temperature.

Work on animals finds thermal safety margins based on ectotherm body temperature to be very different from air temperature-based margins (Bonebrake et al. 2014; Sunday et al. 2014; Pincebourde \& Casas 2015) and behaviour also mediates thermal vulnerability (Kearney, Shine \& Porter 2009; Pincebourde \& Casas 2019). The scale of climate temperature, whether fine scale microclimate in which insects exist, such as leaf boundary layers (Potter, Davidowitz \& Woods 2009), or broader scale climate variables, also influences accuracy of thermal vulnerability assessments (Potter, Davidowitz \& Woods 2009; Pincebourde \& Casas 2015; Pincebourde \& Woods 2020). For plants, great variability exists in reported thermal safety margins. Among the few published leaf-based estimates, margins range from moderate (Perez \& Feeley 2020) to wide (Leon-Garcia \& Lasso 2019), while air-based margins can be negative to wide (Curtis et al. 2016; O'Sullivan et al. 2017; Sastry \& Barua 2017). Variation in width may be influenced by species and latitude (e.g. 
O'Sullivan et al. 2017); however, methodological differences may also play a role. The difference between margins using leaf (body) temperature and local air over more macroenvironmental air temperatures is yet to be quantified.

Leaf temperature is influenced by a range of environmental conditions: air temperature, solar radiation (Fauset et al. 2018; Miller et al. 2021), wind speed (Drake, Raschke \& Salisbury 1970; Leigh et al. 2012), leaf shading (Roden \& Pearcy 1993), as well as plant characteristics such as leaf morphological traits (Leigh et al. 2017; Fauset et al. 2018) and stomatal conductance (Gates, Alderfer \& Taylor 1968; Drake, Raschke \& Salisbury 1970). When air temperatures are high, leaves can avoid heat stress through stomatal conductance (Gates, Alderfer \& Taylor 1968; Drake et al. 2018; Aparecido et al. 2020). Thus, cooling via transpiration offers plants a degree of control over their temperature, maintaining 'partial' homeothermy (Mahan \& Upchurch 1988; Potter, Davidowitz \& Woods 2009; Blonder \& Michaletz 2018), an analogue to ectotherm behavioural avoidance. Reduced water availability can force a trade-off between the maintenance of leaf temperature and maintenance of hydraulic function by closing stomata, triggered by water stress (Fauset et al. 2018). Conditions of water stress therefore can also reduce leaf homeothermy and lead to poikilothermy and megathermy, where leaf temperatures track or exceed air temperature (Blonder \& Michaletz 2018). As such, megathermy is predicted to be particularly common in dry, hot environments such as deserts (Blonder \& Michaletz 2018). However, there is a growing body of knowledge showing temperatures of leaves exceed high air temperatures across a range of environmental conditions and species (Gates, Alderfer \& Taylor 1968; Roden \& Pearcy 1993; Ishida, Toma \& Marjenah 1999; Buchner \& Neuner 2003; Vogel 2009; Krause et al. 2010; Schymanski, Or \& Zwieniecki 2013; Aparecido et al. 2020; Miller et al. 2021). The effect of water limiting conditions on thermal safety margins is under explored (Leon-Garcia \& Lasso 2019) and may help delineate what plant safety margins could be when under less than optimal environmental conditions.

Not only does the relationship between leaf and air temperature vary but increasing temperature can also stimulate increased leaf physiological heat tolerance thresholds by several degrees (Downton, Berry \& Seemann 1984; Seemann, Berry \& Downton 1984; 
Valladares \& Pearcy 1997; Neuner \& Buchner 2012; Buchner et al. 2017; Drake et al. 2018). Increased heat thresholds in response to local environmental (acquired tolerance) triggers can help protect leaves from subsequent high temperatures. Indeed, an upward shift in heat tolerance is potentially an adaptation to extreme leaf temperature (Perez \& Feeley 2020). A shift in heat tolerance means that both components of a thermal safety margin calculation the heat tolerance threshold and leaf temperature - can vary with environmental conditions.

In this study, we used chlorophyll fluorometry to determine photosynthetic thermal tolerance thresholds ( $\left.T_{50}\right)$ of Photosystem II (PSII) in leaves of water-stressed and wellwatered desert plants. We investigated the extent to which thermal thresholds and subsequent estimates of thermal vulnerability might vary depending on the water status of a plant and how ambient temperature was assessed. We aimed to address three hypotheses: 1) that leaves of water-stressed plants would track (poikilothermy) or exceed ambient temperatures (megathermy) and that this would be associated with higher leaf temperatures and heat tolerance thresholds than well-watered plants. When assessing thermal vulnerability using thermal safety margins, we hypothesised 2) that the water status of plants would alter the estimated safety margins, with well-watered plants maintaining wider margins than water-stressed plants. Finally, we predicted 3) that calculations of thermal safety margins using various ambient sources would differ markedly from margins calculated using leaf temperatures.

\section{Materials and methods}

\section{Sampling location and study species plants}

This experiment was conducted at the Australian Arid Lands Botanic Garden, Port Augusta, South Australia $\left(32^{\circ} 28^{\prime} 03.5^{\prime \prime} \mathrm{S}, 137^{\circ} 44^{\prime} 36.7^{\prime \prime} \mathrm{E}\right)$ during the austral summer (December) of 2017. Myoporum montanum (water bush) was selected for study because it has a wide distribution throughout semi-arid and arid Australia (Atlas of Living Australia 2020), with preferred microhabitats along dry water courses with higher water availability than surrounding hard pan areas. Myoporum montanum leaves visibly respond to water stress prior to leaf drop, which is ideal for visually monitoring plants throughout a water-stress 
experiment. Plants were propagated from cuttings taken in the austral winter (July) and well-watered until the beginning of the water treatments in spring (November). Four weeks after the onset of water treatments, physiological sampling occurred over a 12-day period, with $T_{50}$ measurements made every third day (days three, six, nine and 12; Figure 1). All leaves sampled were mature and fully expanded, having developed prior to the water-stress treatments. Due to the amount of leaf material required for the heat tolerance assay, plants from each water treatment were randomly allocated into three 'sub-populations' of 13 plants and re-sampled on each of the four sampling days, with leaves from the plants within each sub-population randomised for each assay. Sampling from multiple individuals meant there was enough similar age leaf material to select fully expanded mature leaves of similar age across plants and sampling days. To ensure that plants used for measuring $T_{50}$ and water potential remained intact, across the two treatments, an additional subset of plants were reserved for monitoring leaf temperature via embedded thermocouples.

\section{Water treatments}

Plants were randomly allocated to each of the watering treatments: well-watered and water stressed. Rainfall was excluded with a rainout shelter made of clear polycarbonate sheeting roof, fine mesh on the sides hanging approximately $40-\mathrm{cm}$ below the roof to reduce incidence of driving rain from the sides (Supplementary Figure S1). Within the rainout shelter, plant blocks were rotated four times during the eight weeks prior to measurement period to minimise position effects on growth. Watering was via a dripper irrigation system which provided $8 \mathrm{~L} / \mathrm{h}$. Well-watered plants $(\mathrm{HW})$ were watered for five minutes (total $0.7 \mathrm{~L}$ ) every day. For water-stress treatments (LW), water was reduced from the well-watered rate in two steps over four weeks in November. First reduction was to three minutes every two days (total $0.4 \mathrm{~L}$ ), followed by the second reduction to two minutes (total $0.26 \mathrm{~L}$ ) every three days. Watering ceased altogether the week prior measurements. During the 12-day measurement period, $0.06 \mathrm{~L}$ was provided by hand to water-stressed treatment plants on days four and nine to prevent plant mortality.

Midday leaf water potentials ( $\Psi_{\text {leaf }}$ ) of each water treatment group were measured daily with a Scholander pressure chamber (PMS Instrument Company, Albany, OR). Once picked, 
leaves were kept in dark humid plastic bags and measured within 10 mins ( $n=3-6$ leaves per watering treatment).

\section{Temperature measurements}

Leaf and local air temperatures were recorded every minute for the 12-day measurement period (Figure 1 ) on eight plants per watering treatment $(n=8)$. Leaf temperatures were measured with t-type thermocouples (Omega Engineering, Singapore; and HOBO; Onset, Bourne, USA) inserted into the centre of the abaxial epidermis layer, away from the midrib. Selected leaves were approximately $10-\mathrm{cm}$ above the soil surface (one leaf per plant). Air temperatures were recorded with eight shielded temperature sensors (iButton ${ }^{\circledR}$, DS1923, San Jose, CA), suspended $10-\mathrm{cm}$ above the potted soil of plants equally dispersed throughout the rainout shelter. Regional temperature data were downloaded from the Australian Bureau of Meteorology (AGBoM 2017) for the "Port Augusta aeronautical station" (station number 018201), situated $3.17 \mathrm{~km}$ from the experimental site.

Thermal tolerance assay ( $T_{50}$ threshold)

Photosynthetic heat tolerance was assessed on leaves collected during the hottest part of the day, to represent the point of highest potential risk of temperature stress. The $T_{50}$ threshold was determined with a temperature assay of the maximum quantum yield of PSII $\left(F_{V} / F_{M}\right)$, following Curtis et al. (2014). $F_{V} / F_{M}$ is a considered a good indicator of the functioning of PSII and is temperature sensitive (Björkman \& Demmig 1987; Maxwell \& Johnson 2000; DeEll \& Toivonen 2003), with declines representing photoinhibition and/or damage to the photosystem (Yamane et al. 1997). Chlorophyll fluorescence measurements were taken with a Mini-PAM fluorometer (Heinz Walz, Effeltrich, Germany). Leaves were collected at the hottest time of day, approximately 15:00, and kept in humid dark plastic bags until experimentation. Five 1-cm leaf sections were placed on moist paper towel and sealed in ziplock plastic bags, then dark-adapted for 30-min prior to initial $F_{V} / F_{M}$ measurements to check leaf function prior to temperature assay. To begin the assay, leaves were submerged in a $28^{\circ} \mathrm{C}$ (summer control temperature) water bath under sub-saturating light conditions for 15-min pre-heat treatment to allow photosystems to light adapt. Leaves were then immediately transferred to their assigned treatment water bath for 15-min then 
transferred to a second $28^{\circ} \mathrm{C}$ bath for $90-\min$. Six temperatures $\left(46,48,50,52,54^{\circ} \mathrm{C}\right.$ and a $28^{\circ} \mathrm{C}$ control) were assayed, totalling 30 leaf disc per replicate sub-population (Supplementary Figure S2). All temperature baths maintained sub-saturating light conditions, were thermo-electrically controlled and monitored with K-type thermocouples (Curtis et al. 2014). After the heat treatment and post-heat 90-min control bath, leaves were stored on moist paper towel in ziplock bags at room temperature in the dark. The final $F_{V} / F_{M}$ was measured approximately 14 hours after heat treatment.

The $T_{50}$ threshold was defined as the temperature at which $F_{V} / F_{M}$ declined by $50 \%$ of the control $F_{V} / F_{M}\left(28^{\circ} \mathrm{C}\right)$, interpolated from a linear equation fit to the two temperatures bracketing the 50\% decline temperature (Knight \& Ackerly 2003; Curtis et al. 2014). The temperature at which there is a $50 \%$ decline in $\mathrm{F}_{\mathrm{V}} / \mathrm{F}_{\mathrm{M}}$ represents the point of irreversible damage to the Photosystem II machinery (Downton and Berry 1982; Schreiber and Berry 1977) and is a widely used metric for assessing thermal limits of PSII (e.g. Bigras 2000; Buchner \& Neuner 2003; Knight \& Ackerly 2003; Krause et al. 2010; Curtis et al. 2014; Sastry \& Barua 2017; Feeley et al. 2020).

\section{Thermal safety margin (TSM)}

The thermal safety margin (TSM) is the difference between the temperature a plant can tolerate biologically (measured here as the $T_{50}$ threshold) and the maximum temperature to which it is exposed in its habitat. For comparison of TSM based on different maximum exposure temperatures, we calculated the safety margins for the maximum recorded leaf temperature, maximum local air temperature adjacent to experimental plants and regional maximum temperature each day of experimental measurement. Maximum leaf and local air temperatures used in TSM calculations were calculated from a 15-min moving average to match the $T_{50}$ assay duration of $15-\mathrm{min}$. Unlike the leaf and local air temperature values, regional maximum temperatures were single values, so leaf and local air temperatures were averaged across plants and sensors and TSM replication was at the $T_{50}$ level $(n=3)$. For qualitative comparison of the effects of unpaired temporal physiological tolerance and air temperature on the TSM, the regional maximum air temperature during the sampling month (December), the sampling year regional maximum air temperature and the regional long term mean maximum summer temperature were downloaded from AGBoM (2019). 


\section{Statistical analysis}

Differences between water treatments for each measured parameter were assessed with linear or linear mixed effects models when the random effect of either day or plant improved the model. Watering treatment and day were fixed categorical factors. Thermal safety margin models also included "measurement type" (leaf, local or regional temperature) as a fixed factor. Models were fitted in R (R Core Team 2018) with the package "nlme" (Pinheiro J et al. 2018). To control for potential temporal autocorrelation, three defined correlation structures were fitted to the models: 1) no correlation structure, 2) compound symmetry structure and 3) a first-order autoregressive structure. Variances were allowed to vary for each factor level of day or watering treatment, depending on the model. Models were compared with AIC and log-likelihood values and those with the lowest AIC value and best fit assumptions were selected. Assumptions of normality, homoscedasticity and degree of autocorrelation were evaluated through graphical assessment of residualfitted scatter plots, histograms, factor level boxplots and autocorrelation figures. Where applicable, pairwise comparisons were analysed with Tukey HSD post-hoc tests in the “emmeans" R package (Lenth 2019). 


\section{Results}

Leaf water potential

Withholding water from plants led to significantly lower and more variable leaf water potentials compared to well-watered plants (Table 1 ). The $\Psi_{\text {leaf }}$ of well-watered plants ranged from -0.1 to $-0.5 \mathrm{MPa}$, whereas water-stressed plants reached a mean minimum of 2.2 MPa on day nine (Figure 2). On days four and nine, leaves of water-stressed plants were visibly wilted, with mean leaf water potentials of -1.7 and $-2.2 \mathrm{MPa}$, respectively. On each occasion, $0.06 \mathrm{~L}$ of water was applied to the water-stressed plants to avoid leaf death. Leaf water potentials subsequently increased (days five, six, ten and eleven) before declining again (Figure 2).

\section{Relationships between leaf and air temperature}

Maximum local air temperature was generally significantly different from maximum leaf temperatures of both well-watered and water-stressed plants (on eight of the 12 days, Table 1; Table S1). Only on day eight was maximum air temperature similar to the maximum leaf temperatures of both water treatments (Figure 3). The temperature of water-stressed leaves peaked at 3 to $5^{\circ} \mathrm{C}$ above the daily maximum air temperature, except for days one, two, seven and eight, when leaf and air maximums were similar to one another. By contrast, leaves of well-watered plants maintained maximum temperatures 3 to $7^{\circ} \mathrm{C}$ lower than maximum air temperatures (Figure 3, Table S1). Consequently, the leaves of water-stressed plants generally reached significantly higher maximum temperatures (up to $57^{\circ} \mathrm{C}$ ) than those of well-watered plants (up to $46^{\circ} \mathrm{C}$, Figure 3; Table 1).

Water availability altered the relationship between leaf and air temperatures. Leaves of well-watered plants generally maintained partial homeothermy (slope less than one) ( $T_{\text {Leaf }} \sim$ $3.93^{\circ} \mathrm{C}( \pm 0.01)+0.76^{\circ} \mathrm{C}( \pm 0.0004) * T_{\text {Air }}, R^{2}=0.9589, p<2.2^{-16}$, Figure $\left.4 A\right)$. Leaves of waterstressed plants on average followed a poikilothermic response (leaf temperatures tracking ambient air temperatures) with the mean slope close to one $\left(T_{\text {Leaf }} \sim-1.26^{\circ} \mathrm{C}( \pm 0.02)+1.04^{\circ} \mathrm{C}\right.$ $( \pm 0.0006) * T_{\text {Air }}, R^{2}=0.9615, p<2.2^{-16}$, Figure $\left.4 \mathrm{~B}\right)$. However, there were also cases of megathermy (leaf temperatures above air temperatures at high temperatures) and partial 
homeothermy (leaf temperatures below ambient at high air temperature), depending on the plant and day (Figure 4B, Supplementary Figure S3).

\section{$T_{50}$ threshold temperatures}

The $\mathrm{T}_{50}$ threshold temperatures varied between 48 and $53^{\circ} \mathrm{C}$ across days and water treatments. Water-stressed plants consistently had significantly higher $\mathrm{T}_{50}$ thresholds than well-watered plants (Table 1). Thresholds also significantly increased over the nine-day period over which they were measured (Table 1), tracking a general increase in air and leaf temperatures (Figure 3). Interestingly, on day nine, when leaf temperatures and air temperatures were notably cooler than the several preceding and subsequent days, $T_{50}$ thresholds remained similarly high across all measurement days $\left(\Delta \mathrm{T}_{50}\right.$ of +0.4 and $-0.7^{\circ} \mathrm{C}$ in well-watered and water-stressed plants, respectively).

\section{Thermal safety margins}

The thermal safety margins calculated with leaf temperatures (difference between $T_{50}$ threshold and in situ leaf temperature) for plants with ample water ranged from 11.6 to $21.4^{\circ} \mathrm{C}$, whereas the margins of water-stress plants ranged from 4.6 to $18.7^{\circ} \mathrm{C}$. The leaf safety margins of well-watered plants were consistently wider (by 3 to $7^{\circ} \mathrm{C}$ ) than those of water-stressed plants, although there was considerable variation among days (Figure 5, Table 2). Changes in safety margins each day depended on increases in $T_{50}$ threshold and changes in leaf temperature, but the latter had a greater influence.

We also investigated how the source of maximum exposure temperature, whether leaf, local or regional air temperature, altered the calculation of thermal safety margins. In wellwatered plants, the use of local air temperature measurements resulted in significantly narrower thermal safety margins $\left(<8^{\circ} \mathrm{C}\right)$ than margins based on leaf temperatures (Figure 5). Using regional air temperature data significantly overestimated the margins around half the time (by $>3^{\circ} \mathrm{C}$ on days three and nine) compared to those calculated with leaf temperatures (Figure 5, Table 2). For plants with low water availability, a more consistent trend occurred. Both local and regional air temperatures always overestimated the breadth of the safety margins relative to leaf temperature-based predictions, although the extent of overestimation varied from 1 to $9^{\circ} \mathrm{C}$ (Figure 5, Table 2). The local and regional air 
temperatures differed up to $8^{\circ} \mathrm{C}$. Part of this difference may have been an effect of the rainout shelter and proximity of the sensors to the ground. Nonetheless, this discrepancy between our local and regional air temperatures was similar to the difference between daily air temperatures logged at the AALBG and recorded regional temperatures (data not shown).

\section{Discussion}

We tested three hypotheses about how water availability and sources of temperature measurement may influence assessments of thermal vulnerability for plants. In support of our first hypothesis, leaf temperatures were markedly influenced by plant water availability and varied throughout the 12-day experimental period. Under maximum local ambient air temperatures, which ranged from 30 to $47^{\circ} \mathrm{C}$, plants with adequate soil water were able to maintain maximum leaf temperatures up to $7^{\circ} \mathrm{C}$ below air temperature and up to $11^{\circ} \mathrm{C}$ lower than maximum leaf temperatures of water-stressed plants (Figure 3). This finding of partialhomeothermy supports recent studies suggesting that plants with adequate water will limit high leaf temperatures during hot conditions by active cooling through transpiration (Urban et al. 2017; Drake et al. 2018; French et al. 2019; Marchin et al. 2020). It was also our expectation that water-stressed plants would have higher photosynthetic heat tolerance thresholds than well-watered plants with occurrences of poikilo- and megathermy, which we also found to be the case. Increased heat thresholds can be triggered by temperature increases (Schreiber \& Berry 1977; Havaux 1992; Buchner \& Neuner 2003; Knight \& Ackerly 2003; Zhu et al. 2018) and in response to water stress (Havaux 1992; Valladares \& Pearcy 1997; Ladjal, Epron \& Ducrey 2000). Which mechanism or the degree to which both may be contributing to the higher heat tolerance thresholds requires further work.

Irrespective of water treatment, we found that $T_{50}$ thresholds did not always follow maximum leaf temperatures. Thresholds tracked the increase in ambient temperature between days three and six, but then stayed high, even after air and leaf temperatures declined from day eight (Figure 3). Of the few studies exploring fine-scale temporal changes in heat threshold with temperature, mismatches in threshold relaxation and leaf temperature have been observed in alpine species (Buchner \& Neuner 2003; Neuner \& Buchner 2012) and delayed relaxation post exposure to a heatwave in a temperate 
Eucalyptus tree (Drake et al. 2018). In other words, the relationship between photosystem thermal tolerance and leaf temperature is not linear (Buchner \& Neuner 2003). It is likely that following and/or alongside the initial acclimatory response, oxidative damage caused by accompanying stress-related processes may also alter photosynthetic heat tolerance (Seemann, Downton \& Berry 1986; Havaux 1992; Epron 1997; Valladares \& Pearcy 1997; Ladjal, Epron \& Ducrey 2000; Ghouil et al. 2003). Either way, the non-linear relationship between leaf temperature and tolerance thresholds has implications for interpreting plant responses to repeated heat events. An increase (or decrease) in air temperature on any given day may not always result in the same degree of change in thermal threshold as another day of the same temperature.

Rates of heat tolerance threshold acclimation with increases in temperature are usually reported to be below unity (from 0 to $\sim 0.3^{\circ} \mathrm{C}$ per ${ }^{\circ} \mathrm{C}$ of warming, Braun, Buchner \& Neuner 2002; Buchner \& Neuner 2003; Sastry \& Barua 2017; Zhu et al. 2018). It is for this reason that thermal safety margins are generally predicted to narrow with future warming, with species having lower heat thresholds expected to be at greater risk (Curtis et al. 2016; Sastry \& Barua 2017; Sastry, Guha \& Barua 2018; Zhu et al. 2018). In the current study, the widest safety margins were associated with the lowest heat thresholds, due to accompanying lower leaf temperatures (Figures 3 and 5), supporting findings in tropical species (Perez \& Feeley 2020). This apparent reversal of risk was the case when leaf, rather than air temperatures were considered in safety margins. Vulnerability to future heat stress events is dependent on a plants ability to regulate leaf temperature as a first line of defence; something that may be more challenging with increasing dry conditions and humidity (De Boeck et al. 2016; Perez \& Feeley 2018). A subsequent line of defence for plants is their ability to increase physiological heat tolerance. Further work pairing leaf temperatures with tolerance measurements under present and warming conditions will advance our ability to estimate more realistic risk of heat stress in plants.

Our second and third hypotheses were that the plant water status and the source of temperature (leaf, local air or average regional air) used to calculate thermal safety margins would alter those margins. Both predictions were supported. When comparing thermal safety margins calculated with leaf, local and regional air temperature, the three estimates were rarely similar, and the availability of water altered the relationship further through 
influencing leaf temperatures (Figure 5). Calculating safety margins using local air temperatures compared to leaf temperatures reduced the mean safety margin by $>5.5^{\circ} \mathrm{C}$ (32\% narrower) for well-watered plants and, conversely, increased it by $1.5^{\circ} \mathrm{C}(12 \%$ wider $)$ for water-stressed plants. Regional air temperature overestimated margins compared with those calculated with leaf temperature by $>1^{\circ} \mathrm{C}(8 \%)$ for well-watered plants and, by $>8^{\circ} \mathrm{C}$ (70\%) when plants were water stressed.

We note that our study was based on only one desert plant species, but the thermal safety margin values we report here are within the range that can be derived from studies on alpine, tropical and US desert species (Knight \& Ackerly 2003; Leon-Garcia \& Lasso 2019; Perez \& Feeley 2020). Our safety margins using regional yearly air temperature values were also similar to those of dry climate tropical species (Sastry \& Barua 2017). Applying the question about under- or overestimation of regional versus leaf temperature to Andean highland species suggests that safety margins would be overestimated by up to $83 \%$, depending on species (back-calculated from Leon-Garcia \& Lasso 2019). In the absence of leaf temperatures, Sastry and Barua (2017) considered three scenarios of potential leaf temperature under future warming, but only considered cases where leaf temperature equalled or exceeded air temperature (an appropriately conservative approach, given a lack of leaf temperature data). However, in light of the extensive partial-homeothermy observed in our well-watered plants, not accounting for water status may mask a lower risk for plants in some conditions. Leaf-to-air-temperature relationships are variable (Blonder et al. 2020). For example, some wet tropical plant species are partially-homeothermic by avoiding high leaf temperatures during peak air temperature (Dong et al. 2017), whereas megathermy can be the case for outer canopy sunlit leaves (Miller et al. 2021). Nevertheless, the influence of partial-homeothermy, poikilothermy and megathermy on safety margins, as demonstrated in our study, are expected to be similar across environmental contexts.

Safety margins calculated on long term climate variables will be, by their nature, spatially and temporally asynchronous with leaf physiological measurements. At a finer scale, our paired safety margins using leaf temperature varied by up to $14^{\circ} \mathrm{C}$ in nine days. This variation was largely driven by changes in leaf temperature, which was an order of magnitude larger $\left(>16^{\circ} \mathrm{C}\right)$ than thresholds $\left(>4^{\circ} \mathrm{C}\right)$. Using a regional monthly maximum, annual maximum or seasonal mean maximum temperature created less variable safety 
margins (see paired vs unpaired error and range bars, Figure 5b). However, we suggest that this reduced variation hides the potential risk of heat stress occurring on a daily scale and, importantly, does not account for plant acclimation or acquired tolerance. Ultimately, leaf temperature provides the essential context for interpreting heat thresholds and making thermal vulnerability assessments.

\section{Recommendations}

A thermal safety margin can be a valuable heuristic indicator of potential vulnerability to increased high temperature extremes (Deutsch et al, 2008), but there are some important aspects to consider for improving and interpreting the estimate for plants. The use of maximum leaf temperatures is a more biologically relevant determination of the risk of leaf heat stress than air temperature. We recognise that the measurement of leaf temperatures in the field, especially for large numbers of species or over time, can be impracticable. We therefore outline the following considerations in determining plant thermal vulnerability with thermal safety margins.

In the absence of leaf temperature data, an air temperature measured more proximal to the plants of interest than a regional weather station is more likely to be representative of the environment leaves may experience; this includes positioning sensors at an appropriate height relative to the ground and considering canopy orientations when collecting leaf samples (Curtis, Knight \& Leigh 2019). If measuring safety margins based on air temperature, consider that they may over- or underestimate the risk, depending on plant water status influence on leaf temperature. If using regional air measurements, ideally one should calibrate with a series of spot leaf temperatures. If this is infeasible, we suggest calibration using the difference in local air temperature to regional station data repeatedly for key points in time, such as the hottest time of day for a given period. The most vital consideration is the pairing of the maximum temperature to the day and time of collection for tolerance testing to capture the biologically relevant daily scale to which thermal safety margins apply. In temporally unpaired scenarios, sampling physiological tolerance over several days, although increasing variation, will also capture potential plastic responses and increase the range of tolerance responses sampled. Accounting for leaf to air relationships is 
clearly fundamental to improving estimates of current and future predicted plant thermal safety margins.

\section{References}

AGBoM (2017) Daily maximum temperature Port Augusta Aero. Australian Government Bureau of Meteorology.

AGBoM (2019) Climate statistics for Australian Locations: Port Augusta AERO. Australian Government Bureau of Meteorology.

Aparecido, L.M.T., Woo, S., Suazo, C., Hultine, K.R. \& Blonder, B. (2020) High water use in desert plants exposed to extreme heat. 23, 1189-1200.

Atlas of Living Australia (2020) Atlas of Living Australia, Myoporum montanum R.Br. website at https://bie.ala.org.au/species/https://id.biodiversity.org.au/node/apni/7957707.

Bigras, F.J. (2000) Selection of white spruce families in the context of climate change: heat tolerance. Tree Physiology, 20, 1227-1234.

Björkman, O. \& Demmig, B. (1987) Photon yield of O2 evolution and chlorophyll fluorescence characteristics at $77 \mathrm{~K}$ among vascular plants of diverse origins. Planta, 170, 489-504.

Blonder, B., Escobar, S., Kapás, R.E. \& Michaletz, S.T. (2020) Low predictability of energy balance traits and leaf temperature metrics in desert, montane and alpine plant communities. Functional Ecology, 34, 1882-1897.

Blonder, B. \& Michaletz, S.T. (2018) A model for leaf temperature decoupling from air temperature. Agricultural and Forest Meteorology, 262, 354-360.

Bonebrake, T.C., Boggs, C.L., Stamberger, J.A., Deutsch, C.A. \& Ehrlich, P.R. (2014) From global change to a butterfly flapping: biophysics and behaviour affect tropical climate change impacts. Proc Biol Sci, 281.

Braun, V., Buchner, O. \& Neuner, G. (2002) Thermotolerance of photosystem 2 of three alpine plant species under field conditions. Photosynthetica, 40, 587-595.

Buchner, O. \& Neuner, G. (2003) Variability of heat tolerance in alpine plant species measured at different altitudes. Arctic Antarctic and Alpine Research, 35, 411-420. 
Buchner, O., Roach, T., Gertzen, J., Schenk, S., Karadar, M., Stöggl, W., Miller, R., Bertel, C., Neuner, G. \& Kranner, I. (2017) Drought affects the heat-hardening capacity of alpine plants as indicated by changes in xanthophyll cycle pigments, singlet oxygen scavenging, $\alpha$-tocopherol and plant hormones. Environmental and Experimental Botany, 133, 159-175.

Cook, A.M., Berry, N., Milner, K.V. \& Leigh, A. (2021) Data from: Water availability influences thermal safety margins for leaves. Dryad Digital Repository. https://doi.org/10.5061/dryad.tht76hf04.

Curtis, E.M., Gollan, J., Murray, B.R. \& Leigh, A. (2016) Native microhabitats better predict tolerance to warming than latitudinal macro-climatic variables in arid-zone plants. Journal of Biogeography, 43, 1156-1165.

Curtis, E.M., Knight, C.A. \& Leigh, A. (2019) Intracanopy adjustment of leaf-level thermal tolerance is associated with microclimatic variation across the canopy of a desert tree (Acacia papyrocarpa). Oecologia, 189, 37-46.

Curtis, E.M., Knight, C.A., Petrou, K. \& Leigh, A. (2014) A comparative analysis of photosynthetic recovery from thermal stress: a desert plant case study. Oecologia, $175,1051-1061$.

De Boeck, H.J., Van De Velde, H., De Groote, T. \& Nijs, I. (2016) Ideas and perspectives: Heat stress: More than hot air. Biogeosciences, 13, 5821-5825.

DeEll, J.R. \& Toivonen, P. (2003) Practical Applications of Chlorophyll Fluorescence in Plant Biology. Springer Science \& Business Media, US.

Deutsch, C.A., Tewksbury, J.J., Huey, R.B., Sheldon, K.S., Ghalambor, C.K., Haak, D.C. \& Martin, P.R. (2008) Impacts of climate warming on terrestrial ectotherms across latitude. Proceedings of the National Academy of Sciences, 105, 6668-6672.

Dong, N., Prentice, I.C., Harrison, S.P., Song, Q.H. \& Zhang, Y.P. (2017) Biophysical homoeostasis of leaf temperature: A neglected process for vegetation and landsurface modelling. Global Ecology Biogeography, 26, 998-1007.

Downton, W.J.S. \& Berry, J.A. (1982) Chlorophyll fluorescence at high-temperature. Biochimica Et Biophysica Acta, 679, 474-478.

Downton, W.J.S., Berry, J.A. \& Seemann, J.R. (1984) Tolerance of photosynthesis to hightemperature in desert plants. Plant Physiology, 74, 786-790.

This article is protected by copyright. All rights reserved 
Drake, B.G., Raschke, K. \& Salisbury, F.B. (1970) Temperature and transpiration resistances of xanthium leaves as affected by air temperature, humidity, and wind speed. Plant Physiology, 46, 324-330.

Drake, J.E., Tjoelker, M.G., Vårhammar, A., Medlyn, B.E., Reich, P.B., Leigh, A., Pfautsch, S., Blackman, C.J., López, R., Aspinwall, M.J., Crous, K.Y., Duursma, R.A., Kumarathunge, D., De Kauwe, M.G., Jiang, M., Nicotra, A.B., Tissue, D.T., Choat, B., Atkin, O.K. \& Barton, C.V.M. (2018) Trees tolerate an extreme heatwave via sustained transpirational cooling and increased leaf thermal tolerance. Global Change Biology, 24, 1-13.

Epron, D. (1997) Effects of drought on photosynthesis and on the thermotolerance of photosystem II in seedlings of cedar (Cedrus atlantica and C. libani). Journal of Experimental Botany, 48, 1835-1841.

Fauset, S., Freitas, H.C., Galbraith, D.R., Sullivan, M.J.P., Aidar, M.P.M., Joly, C.A., Phillips, O.L., Vieira, S.A. \& Gloor, M.U. (2018) Differences in leaf thermoregulation and water use strategies between three co-occurring Atlantic forest tree species. Plant, Cell \& Environment, 41, 1618-1631.

Feeley, K., Martinez-Villa, J., Perez, T., Silva Duque, A., Triviño Gonzalez, D. \& Duque, A. (2020) The Thermal Tolerances, Distributions, and Performances of Tropical Montane Tree Species. Frontiers in Forests and Global Change, 3, 25.

French, K., Jansens, I.B., Ashcroft, M.B., Ecroyd, H. \& Robinson, S.A. (2019) High tolerance of repeated heatwaves in Australian native plants. Austral Ecology, 44, 597-608.

Gallagher, R.V., Allen, S. \& Wright, I.J. (2019) Safety margins and adaptive capacity of vegetation to climate change. Scientific Reports, 9, 1-11.

Gates, D.M., Alderfer, R. \& Taylor, E. (1968) Leaf Temperatures of Desert Plants. Science, 159, 994-995.

Ghouil, H., Montpied, P., Epron, D., Ksontini, M., Hanchi, B. \& Dreyer, E. (2003) Thermal optima of photosynthetic functions and thermostability of photochemistry in cork oak seedlings. Tree Physiology, 23, 1031-1039.

Havaux, M. (1992) Stress Tolerance of Photosystem II in Vivo: Antagonistic Effects of Water, Heat, and Photoinhibition Stresses. Plant Physiology, 100, 424-432.

This article is protected by copyright. All rights reserved 
Huey, R.B., Deutsch, C.A., Tewksbury, J.J., Vitt, L.J., Hertz, P.E., Alvarez Pérez, H.J. \& Garland, T., Jr. (2009) Why tropical forest lizards are vulnerable to climate warming. Proc Biol Sci, 276, 1939-1948.

Ishida, A., Toma, T. \& Marjenah (1999) Leaf gas exchange and chlorophyll fluorescence in relation to leaf angle, azimuth, and canopy position in the tropical pioneer tree, Macaranga conifera. Tree Physiology, 19, 117-124.

Kearney, M., Shine, R. \& Porter, W.P. (2009) The potential for behavioral thermoregulation to buffer "cold-blooded" animals against climate warming. Proceedings of the National Academy of Sciences, 106, 3835-3840.

Knight, C.A. \& Ackerly, D.D. (2003) Evolution and plasticity of photosynthetic thermal tolerance, specific leaf area and leaf size: congeneric species from desert and coastal environments. New Phytologist, 160, 337-347.

Krause, G.H., Winter, K., Krause, B., Jahns, P., García, M., Aranda, J. \& Virgo, A. (2010) Hightemperature tolerance of a tropical tree, Ficus insipida: methodological reassessment and climate change considerations. Functional Plant Biology, 37, 890900.

Ladjal, M., Epron, D. \& Ducrey, M. (2000) Effects of drought preconditioning on thermotolerance of photosystem II and susceptibility of photosynthesis to heat stress in cedar seedlings. Tree Physiology, 20, 1235-1241.

Leigh, A., Sevanto, S., Ball, M.C., Close, J.D., Ellsworth, D.S., Knight, C.A., Nicotra, A.B. \& Vogel, S. (2012) Do thick leaves avoid thermal damage in critically low wind speeds? New Phytologist, 194, 477-487.

Leigh, A., Sevanto, S., Close, J.D. \& Nicotra, A.B. (2017) The influence of leaf size and shape on leaf thermal dynamics: does theory hold up under natural conditions? Plant, Cell \& Environment, 40, 237-248.

Lenth, R. (2019) emmeans: Estimated Marginal Means, aka Least-Squares Means. R package version 1.3.5.1. .

Leon-Garcia, I.V. \& Lasso, E. (2019) High heat tolerance in plants from the Andean highlands: Implications for paramos in a warmer world. PLOS ONE, 14, e0224218-e0224218.

Mahan, J.R. \& Upchurch, D.R. (1988) Maintenance of constant leaf temperature by plantsI. Hypothesis-limited homeothermy. Environmental and Experimental Botany, 28, 351-357.

This article is protected by copyright. All rights reserved 
Marchin, R.M., Ossola, A., Leishman, M.R. \& Ellsworth, D.S. (2020) A Simple Method for Simulating Drought Effects on Plants. Frontiers in Plant Science, 10, 1715.

Maxwell, K. \& Johnson, G.N. (2000) Chlorophyll fluorescence-a practical guide. Journal of Experimental Botany, 51, 659-668.

Miller, B.D., Carter, K.R., Reed, S.C., Wood, T.E. \& Cavaleri, M.A. (2021) Only sun-lit leaves of the uppermost canopy exceed both air temperature and photosynthetic thermal optima in a wet tropical forest. Agricultural and Forest Meteorology, 301-302, 108347.

Neuner, G. \& Buchner, O. (2012) Dynamics of Tissue Heat Tolerance and Thermotolerance of PS II in Alpine Plants. Plants in Alpine Regions: Cell Physiology of Adaption and Survival Strategies (ed. C. Lütz), pp. 61-74. Springer Vienna, Vienna.

O'Sullivan, O.S., Heskel, M.A., Reich, P.B., Tjoelker, M.G., Weerasinghe, L.K., Penillard, A., Zhu, L., Egerton, J.J.G., Bloomfield, K.J., Creek, D., Bahar, N.H.A., Griffin, K.L., Hurry, V., Meir, P., Turnbull, M.H. \& Atkin, O.K. (2017) Thermal limits of leaf metabolism across biomes. Global Change Biology, 23, 209-223.

Perez, T.M. \& Feeley, K.J. (2018) Increasing Humidity Threatens Tropical Rainforests. Frontiers in Ecology and Evolution, 6, 68.

Perez, T.M. \& Feeley, K.J. (2020) Photosynthetic heat tolerances and extreme leaf temperatures. Functional Ecology, 34, 2236-2245.

Pincebourde, S. \& Casas, J. (2015) Warming tolerance across insect ontogeny: influence of joint shifts in microclimates and thermal limits. Ecology, 96, 986-997.

Pincebourde, S. \& Casas, J. (2019) Narrow safety margin in the phyllosphere during thermal extremes. Proc Natl Acad Sci U S A, 116, 5588-5596.

Pincebourde, S. \& Woods, H.A. (2020) There is plenty of room at the bottom: microclimates drive insect vulnerability to climate change. Current Opinion in Insect Science, 41, 6370.

Pinheiro J, Bates D, DebRoy S, Sarkar D \& R Core Team (2018) nlme: Linear and Nonlinear Mixed Effects Models. R package version 3.1-137.

Potter, K., Davidowitz, G. \& Woods, H.A. (2009) Insect eggs protected from high temperatures by limited homeothermy of plant leaves. Journal of Experimental Biology, 212, 3448-3454.

This article is protected by copyright. All rights reserved 
R Core Team (2018) R: A language and environment for statistical computing. R Foundation for Statistical Computing, Vienna, Austria.

Roden, J.S. \& Pearcy, R.W. (1993) The effect of flutter on the temperature of poplar leaves and its implications for carbon gain. Plant, Cell \& Environment, 16, 571-577.

Sastry, A. \& Barua, D. (2017) Leaf thermotolerance in tropical trees from a seasonally dry climate varies along the slow-fast resource acquisition spectrum. Scientific Reports, 7, 11246 .

Sastry, A., Guha, A. \& Barua, D. (2018) Leaf thermotolerance in dry tropical forest tree species: relationships with leaf traits and effects of drought. AoB Plants, 10, plx070.

Schreiber, U. \& Berry, J.A. (1977) Heat-induced changes of chlorophyll fluorescence in intact leaves correlated with damage of the photosynthetic apparatus. Planta, 136, 233238.

Schymanski, S.J., Or, D. \& Zwieniecki, M. (2013) Stomatal Control and Leaf Thermal and Hydraulic Capacitances under Rapid Environmental Fluctuations. PLOS ONE, 8, 16.

Seemann, J.R., Berry, J.A. \& Downton, W.J.S. (1984) Photosynthetic response and adaptation to high-temperature in desert plants - a comparison of gas-exchange and fluorescence methods for studies of thermal tolerance. Plant Physiology, 75, 364368.

Seemann, J.R., Downton, W.J.S. \& Berry, J.A. (1986) Temperature and leaf osmotic potential as factors in the acclimation of photosynthesis to high-temperature in desert plants. Plant Physiology, 80, 926-930.

Sunday, J.M., Bates, A.E., Kearney, M.R., Colwell, R.K., Dulvy, N.K., Longino, J.T. \& Huey, R.B. (2014) Thermal-safety margins and the necessity of thermoregulatory behavior across latitude and elevation. Proceedings of the National Academy of Sciences, 111, 5610-5615.

Urban, J., Ingwers, M.W., McGuire, M.A. \& Teskey, R.O. (2017) Increase in leaf temperature opens stomata and decouples net photosynthesis from stomatal conductance in Pinus taeda and Populus deltoides x nigra. Journal of Experimental Botany, 68, 17571767.

Valladares, F. \& Pearcy, R.W. (1997) Interactions between water stress, sun-shade acclimation, heat tolerance and photoinhibition in the sclerophyll Heteromeles arbutifolia. Plant, Cell \& Environment, 20, 25-36.

This article is protected by copyright. All rights reserved 
Vogel, S. (2009) Leaves in the lowest and highest winds: temperature, force and shape. New Phytologist, 183, 13-26.

Yamane, Y., Kashino, Y., Koike, H. \& Satoh, K. (1997) Increases in the fluorescence Fo level and reversible inhibition of Photosystem II reaction center by high-temperature treatments in higher plants. Photosynthesis Research, 52, 57-64.

Zhu, L., Bloomfield, K.J., Hocart, C.H., Egerton, J.J.G., O'Sullivan, O.S., Penillard, A., Weerasinghe, L.K. \& Atkin, O.K. (2018) Plasticity of photosynthetic heat tolerance in plants adapted to thermally contrasting biomes. Plant, Cell \& Environment, 41, 1-12.

\section{Supporting Information}

Additional supporting information may be found online in the Supporting Information section. 


\section{Figure Legends}

Figure 1. Average local air and leaf temperatures throughout the 12-day summer measurement period, recorded every minute. Different coloured lines indicate leaf temperatures for well-watered plants (HW, pale blue), water-stressed plants (LW, red), local air temperature (solid black) and regional maximum air temperature at 3pm (Air, dashed); vertical grey dashed lines indicate when $T_{50}$ thresholds were sampled.

Figure 2. Mean $( \pm S E)$ midday leaf water potentials of well-watered $(H W)$ and water stressed (LW) plants over the 12 measurement days. Blue vertical shaded bar indicates the starting leaf water potentials before the application of the water treatment, eight days prior to the first experimental measurements. Grey dashed lines indicate days on which $T_{50}$ thresholds were measured and stars indicate a significant difference between HW (blue circles) and LW (red squares) leaf water potentials, based on Tukey post-hoc tests, where $p<0.05$.

Figure 3. The mean maximum ( $\pm \mathrm{SE})$ leaf $\left(\mathrm{T}_{\text {Leaf }}\right)$ and local air $\left(\mathrm{T}_{\text {Air }}\right)$ temperatures measured every day and mean $( \pm \mathrm{SE}) \mathrm{T}_{50}$ thresholds every three days during the 12-day measurement period. Temperatures were measured every minute. Blue circles indicate well-watered leaves (HW); red squares and diamonds indicate water-stressed leaves (LW) and black triangles, air temperature. Open symbols are leaf and air temperatures; filled symbols are $T_{50}$ threshold temperatures. Vertical dashed lines indicate days on which $T_{50}$ thresholds were measured.

Figure 4. Relationship between leaf and local air temperatures for well-watered (a) and water-stressed plants (b). Values on the 1:1 line at high air temperatures indicate that leaves are tracking air temperature (poikilothermy); values below the line show leaf temperatures cooler than air (partial homeothermy) and above the line are leaves warmer than air temperature (megathermy). Linear relationship fit to all $\mathrm{T}_{\text {air }}: \mathrm{T}_{\text {leaf }}$ measurements, individual short lines were fits per plant per day.

Figure 5. a) Daily changes in thermal safety margins (TSM, means ( $\pm S E)$ ) for $M$. montanum determined with three temperature sources: maximum leaf temperature (circles), mean maximum local air temperature (triangles) and maximum regional temperature (squares). Each margin was calculated for well-watered (blue) and water-stressed plants (red) on the 
day of $T_{50}$ threshold $\left(T_{50}\right)$. To match the $T_{50}$ assay duration of 15-min, maximum leaf and air temperatures were calculated from a 15-min moving average rather than the sampled 1min data of Figure 2. Letters indicate significant differences within water treatment comparisons ( $p<0.001)$, with HW comparisons in lower case and LW in upper case. b) Mean TSM ( \pm SE and range) calculated on temporally paired and temporally unpaired measurements of temperature and physiological heat threshold. Paired measurements (black closed symbols), i.e., those measured on the same day as $T_{50}$, include daily maximum leaf temperature, maximum local air temperature and maximum regional air temperature averaged across all measurement days. Unpaired measurements (open symbols) are TSMs calculated with the regional monthly maximum air temperature of the experimental month (December, $45.9^{\circ} \mathrm{C}$ ), regional yearly maximum air temperature $\left(\mathrm{MxAT}, 47.2^{\circ} \mathrm{C}\right)$ and the regional long term mean maximum summer temperature (MMxAT, $33.3^{\circ} \mathrm{C}$ ). Grey vertical bars through points indicate the range in mean TSM across all experimental days and water treatments. 


\section{Tables}

Table 1. Linear and linear mixed model results for measured parameters: leaf water potential ( $\left.\Psi_{\text {Leaf }}\right)$, maximum temperature $\left(T_{\max }\right)$ and heat tolerance threshold $\left(T_{50}\right)$. For variables $\Psi_{\text {Leaf }}$ and $T_{50}$, treatment levels were well-watered $(H W)$ and water stressed (LW), while for $T_{\max }$, treatment levels also included air temperature.

\begin{tabular}{|c|c|c|c|c|c|c|c|c|c|}
\hline & $\Psi_{\text {Leaf }}$ & & & $\mathbf{T}_{\max }$ & & & $T_{50}$ & & \\
\hline Fixed effects & $d f$ & F-value & $p$-value & $d f$ & F-value & $p$-value & $\mathrm{df}$ & F-value & $p$-value \\
\hline Intercept & 1,95 & 207.1882 & $<0.0001$ & 1,217 & 8117.097 & $<0.0001$ & 1,19 & 131538.6 & $<0.0001$ \\
\hline Treatment & 1,95 & 69.61736 & $<0.0001$ & 2,21 & 26.41 & $<0.0001$ & 1,19 & 47.8 & $<0.0001$ \\
\hline Day & 11,95 & 5.74812 & $<0.0001$ & 11,217 & 475.475 & $<0.0001$ & 3,19 & 14.1 & $<0.0001$ \\
\hline Treatment* Day & 11,95 & 7.94377 & $<0.0001$ & 22,217 & 10.202 & $<0.0001$ & & ns & ns \\
\hline Random effects & & \multicolumn{8}{|c|}{ Variance (\%) } \\
\hline Individual plant & & na & na & & 3.457 & (86.4) & & na & na \\
\hline Residual & & na & na & & 0.544 & $(13.6)$ & & na & na \\
\hline Total variance & 119,95 & 0.014 & & & 4.0017 & & 24,19 & 0.686 & \\
\hline
\end{tabular}

This article is protected by copyright. All rights reserved 
Table 2. Linear model results for thermal safety margin (TSM) comparisons investigating the influence and interaction of plant water availability (Treatment; HW or LW), variability between days (Day) and source of temperature (Measurement; $\mathrm{T}_{\text {leaf }}, \mathrm{T}_{\text {air }}, \mathrm{T}_{\text {regional }}$ ) on the TSM estimation.

\begin{tabular}{llll}
\hline Factors & \multicolumn{2}{l}{ TSM } & \\
\cline { 2 - 4 } Fixed effects & $\mathrm{df}$ & F-value & p-value \\
\hline Intercept & 1,48 & 120861.42 & $<0.0001$ \\
Treatment LW & 1,48 & 10.39 & 0.0023 \\
Day & 3,48 & 6109.8 & $<0.0001$ \\
Treatment* Day & 3,48 & 12.08 & $<0.0001$ \\
Measurement ( $\left.\mathrm{T}_{\text {leaf, }} \mathrm{T}_{\text {air, }} \mathrm{T}_{\text {regional }}\right)$ & 2,48 & 1991.75 & $<0.0001$ \\
Treatment* Measurement & 2,48 & 544.49 & $<0.0001$ \\
Day*Measurement & 6,48 & 31.1 & $<0.0001$ \\
Treatment*Day*Measurement & 6,48 & 15.86 & $<0.0001$ \\
Residual variance & 0.597 & & \\
\hline
\end{tabular}




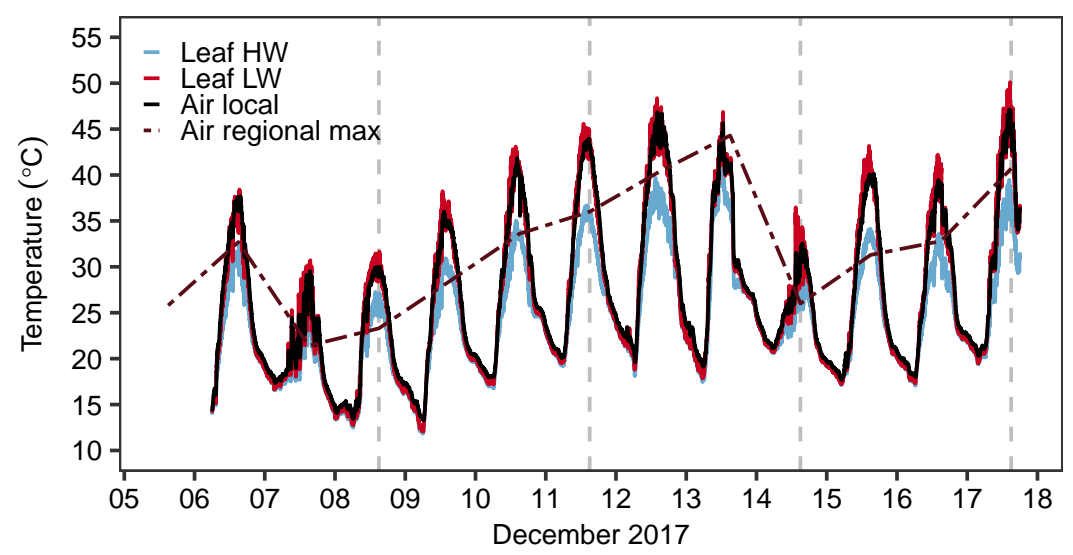




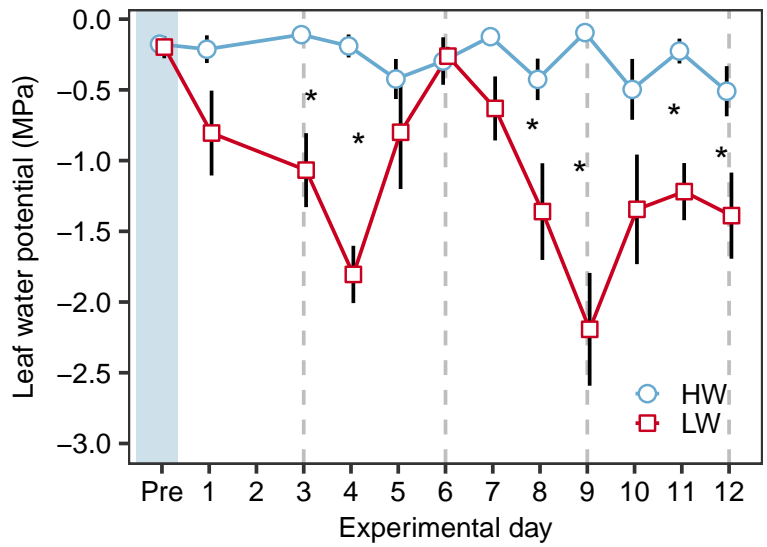




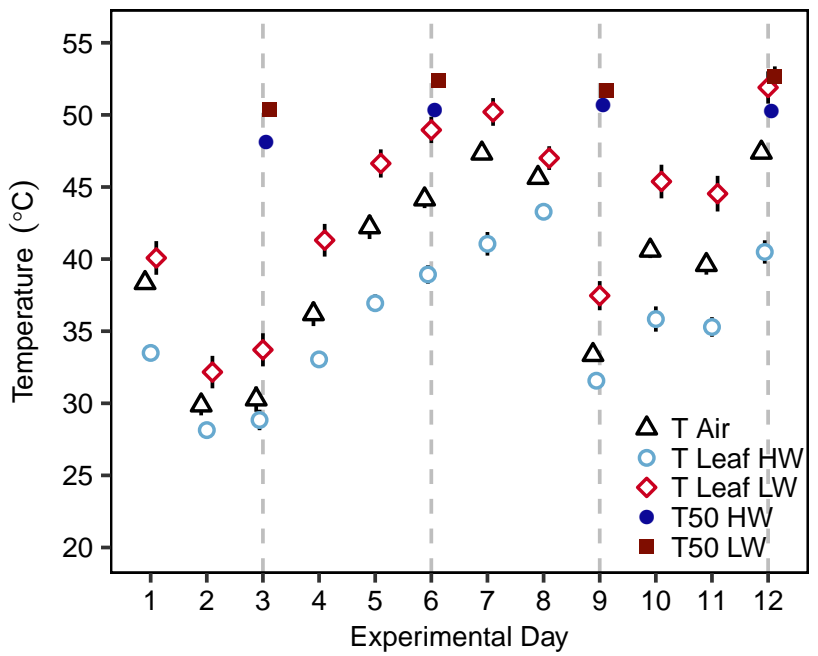



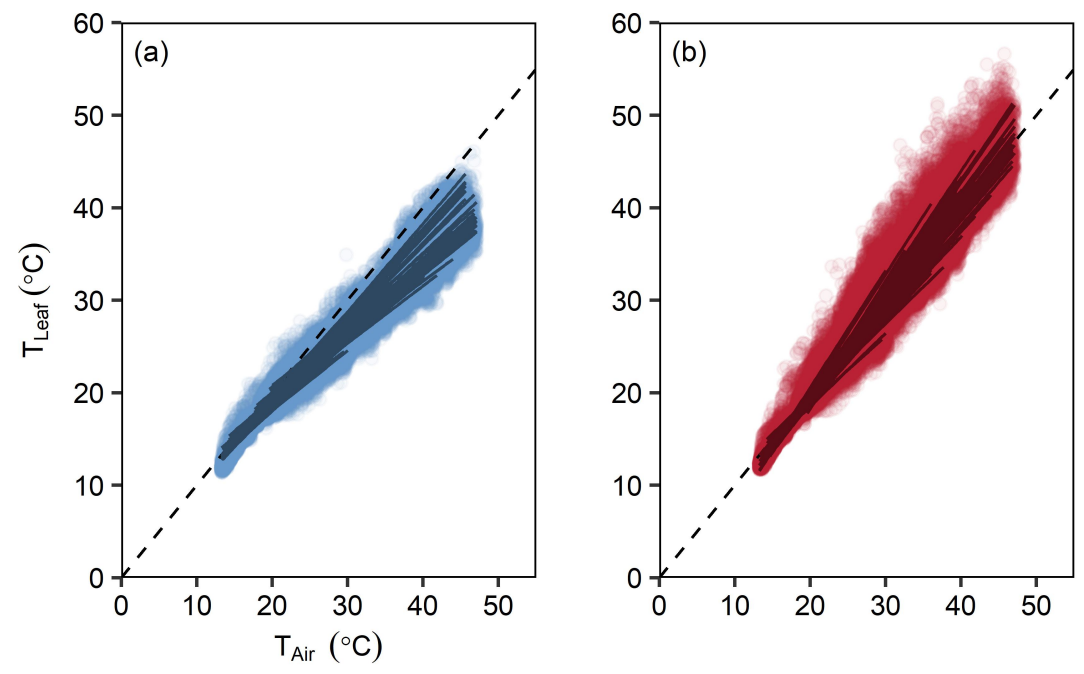

fec_13868_f4.jpg

This article is protected by copyright. All rights reserved 


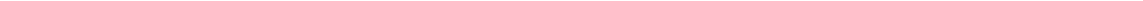

